\title{
TTR
}

Traduction, terminologie, rédaction

\section{Perspectives on Cognition, Translation, and Translators}

\section{Candace Séguinot}

Volume 30, numéro 1-2, 1er semestre-2e semestre 2017

La traductologie en mouvement

Translations Studies: A Forward-Moving Discipline

URI : https://id.erudit.org/iderudit/1060024ar

DOI : https://doi.org/10.7202/1060024ar

Aller au sommaire du numéro

\section{Éditeur(s)}

Association canadienne de traductologie

ISSN

0835-8443 (imprimé)

1708-2188 (numérique)

Découvrir la revue

Citer cet article

Séguinot, C. (2017). Perspectives on Cognition, Translation, and Translators. TTR, 30(1-2), 195-214. https://doi.org/10.7202/1060024ar

\section{Résumé de l'article}

Depuis trente ans, la façon dont on appréhende le processus de la traduction a beaucoup changé : on comprend mieux que la traduction n'est pas un seul et unique phénomène, qu'il faut tenir compte des variations et des contextes. De plus, les méthodes employées pour étudier les processus de la traduction ont évolué, ce qui fait que l'on comprend mieux comment les données langagières sont organisées dans le cerveau et comment on y accède. On peut ainsi examiner de plus près les aspects physiques et l'organisation du travail des traducteurs professionnels. 


\title{
Perspectives on Cognition, Translation, and Translators
}

\author{
Candace Séguinot \\ York University
}

\begin{abstract}
Looking back on the past thirty years, this article traces the development of our understanding of the translation process, how we study it, how we have moved from essentialism to an appreciation of variation and context, what we've learned about how the mind stores and accesses language, and how the specifics of the translating environment affects the work of the professional translator.
\end{abstract}

Keywords: professional translation, translation process, cognitive aspects of translation, translation ergonomics

\section{Résumé}

Depuis trente ans, la façon dont on appréhende le processus de la traduction a beaucoup changé : on comprend mieux que la traduction n'est pas un seul et unique phénomène, qu'il faut tenir compte des variations et des contextes. De plus, les méthodes employées pour étudier les processus de la traduction ont évolué, ce qui fait que l'on comprend mieux comment les données langagières sont organisées dans le cerveau et comment on y accède. On peut ainsi examiner de plus près les aspects physiques et l'organisation du travail des traducteurs professionnels.

Mots-clés : traduction professionnelle, processus de la traduction, aspects cognitifs de la traduction, ergonomie de la traduction en milieu de travail

\section{Introduction}

In the first volume of TTR, I published an article about explicitation in translation based on an empirical study. The article began with the goals of empirical studies as I saw them then and as I have continued to see them:

Empirical studies can provide evidence about how people translate, can help us understand how languages are stored and accessed in the brain, and provide clues as to how meaning is received and encoded in language and transferred between languages. (Séguinot, 1988, p.106) 
What has changed in my work and in the work of others looking at translation as a process is first the methodologies used in these studies and second the particular focus of hypothesis-testing agendas in the search to strengthen the scientific credibility of the findings of previous research. Before reporting on a current research project, I would like to trace the progress that has been made in techniques for studying the relationship between cognition and translation and the growth of our understanding of some of the questions about language, meaning, and translation.

\section{The evolution of process studies}

To begin with, translation studies as an academic discipline grew out of departments in linguistics, literature, or language studies. The particular interest of each area coloured the objects of study, for example the translation of literature privileged working with literary translation and therefore well-written, creative texts. Translation within language studies focussed on building skills in grammar and vocabulary while translation as a specialized branch of applied linguistics resulted in comparative or contrastive analysis.

The descriptions of the methods used by translators and the cognitive processes underlying them came first out of this comparative approach. Jean-Paul Vinay and Jean Darbelnet's Stylistique comparée du français et de l'anglais, first published in 1958, suggested that there are units of translation which are "lexicological units within which lexical elements are grouped together to form a single element of thought. It would be more correct to say: the unit of translation is the predominant element of thought within such a segment of the utterance" (Vinay and Darbelnet, 1995, p. 21). Implicitly this expresses a hypothesis for the way languages are associated in the brain: a dictionary-like association of language and thought, an analysis which is consistent with a structural approach. Similarly their description of translation methodology referred to relationships between parts of texts and their translation: their method for translating was divided into seven procedures (ibid., pp.30-40) based on a comparison of instances of source and target texts that illustrated differences.

The prescriptive approach to translation began to be adapted to the new programs in higher education preparing people to enter translation as a profession. Peter Newmark described his goal in $A$ Textbook of Translation (1988) as helping people become translators 
and he specifically said that he was not theorizing about the way people translated. The translating procedures he suggested were, he said, purely operational. The development of descriptive studies of translation that were based in observation began with field studies. Studies of natural translation (Harris, 1977; Harris and Sherwood, 1978), meaning situations where children were interpreting for their family members, demonstrated that the ability to translate was coextensive with bilingualism depending on the degree of mastery of the two languages. At the same time studies of bilingualism in the field of psychology led to hypotheses about the relationship between languages in the brain. A number of psychologists focused on language acquisition and the differences in acquisition depending on whether the languages were learned at a young age or later in life, or more accurately in the same environment or in different environments. By environment it was thought that children who learned two languages at home growing up would have a grammar that was different from someone who learned a second language in a different environment, like school. The person who learned their second language at home would be using the first language as a base and use that one meaning system while the person who learned their languages in two different environments would have two separate meaning systems. The person who learned two languages in the same environment was labelled a "compound bilingual" and the person who learned the second language in a different environment was called a "coordinate bilingual" (Ervin and Osgood, 1954). There was speculation about the ability to translate, with some psychologists arguing that only compound bilinguals could translate well and others that only co-ordinate bilinguals could translate easily because they had established links of referential identity between languages (Werner and Schoepfle, 1987, p. 358).

This question of links between languages and links between lexical representations and conceptual representations is key for understanding how translation works and how language is organized in the brain. Do bilinguals share conceptual representations between their languages or are conceptual representations tied to the lexical representations of each language (de Groot, 1997)? Moving past the structural theoretical accounts of types of bilingualism, psychologists set up experiments to investigate the nature of the relationship between languages using variables like reaction time to pairs of words and later phrases. 
Translation scholars who wanted to find a scientific way of investigating the nature of translation needed a way to carry out experimental research beyond words or phrases. The work of psychologists Allen Newell and Herbert Simon (1972) on problem-solving in other domains provided an insight that allowed a shift from the static study of the products of translation to the process itself. From early work in translation theory on decisions in translation (Levý, 1967) there has been a thread first conceptualizing (e.g., Newmark, 1988, pp. 21-22), and later investigating (e.g., the Pacte group, 2008, pp. 106-107) the dynamics of translation as a series of problemsolving decisions.

The thinking-aloud protocol, or TAP, was the method used to study dynamic decision-making processes. Subjects were asked to verbalize everything that went through their heads as they were completing a task. However, according to K. Anders Ericsson and Herbert Simon (1980 and 1984), the only information available to subjects is the information in short-term memory. As experts automatize their processes, they do not have access to the reasons for making decisions at the point where the translation is being produced and so do not verbalize thoughts in the same way that novices do. It has also been shown that asking subjects to speak as they translate interferes with the process by slowing it down (Jensen and Jakobsen, 2000; Jakobsen, 2003). The solution has been to employ triangulation, meaning using more than one method to gather data (Alves, 2003).

When observational studies of the translation process were in their infancy in the 1980s there was the assumption that variables could be isolated for study. These variables included the search for translation units and an expert versus novice distinction. The goal was to validate what had been written about the way translators work, document the competencies needed for successful translation, and incorporate productive strategies into classroom teaching. Rather rapidly it became clear that labelling students as naïve or expert, or at introductory or advanced levels of learning in a translation program, was less likely to produce the strategies used in the workplace than looking at professional versus non-professional translators.

So a question was raised as to the ecological validity of these studies. Were you really studying the processes of translation or watching the coping strategies of students who had not developed the skills of professionals? The numbers of subjects in any observational study were small given the need to work with a population with 
specific skills, and the search for relevant data meant that there was a certain subjectivity in deciding whether success would be measured by someone completing a translation or whether there would be a quality assessment of some kind. The assumption seemed to be that whatever evidence was found would uncover cognitive processes that were shared and best practices related to successful results. Even using professional translators as subjects produced evidence of subcultures depending on where the translator worked and whether the business climate or their freelance practices differed (Jääskeläinen, 1990 and 1999). It also became clear that not all professional translators were experts, and in some cases where subjects included both students and professionals, some students performed better than some professional translators (see Göpferich, 2009).

Another question is whether the cognitive processes in any one individual translating is necessarily the same process in another. It turns out that as with cognitive styles in writing, some translators do not type out the part of the translation they are working on until they know how they want to phrase it while others type their translations as they read the source text and go back even as they type to revise it (Asadi and Séguinot, 2005). Even competent translators faced with texts to translate outside their area of expertise or in experimental situations where they do not have access to the tools they normally use could underperform.

To sum up, the last thirty years have seen the development of more scientific approaches to the study of the translation process and the cognitive processes underlying the production of a translation. With time, as is the case with scientific progress, the methodologies have been modified. Recent developments in technology have affected both the way translation is produced and delivered and how the processes can be studied. In addition there is the fundamental question of incorporating the results of observational studies into classroom training. Are the graduates of translation programs being prepared for the kinds of work that they will be expected to do? What are the skills that are most useful in a rapidly changing work environment?

\section{The impact of technology on translation and translation research}

The study of translation processes became both easier and more difficult with the impact of technology on translation and on the study of translation. For instance, it became easier to produce reliable 
research data with the introduction of the software program Translog to capture the keystrokes produced during translating (Jakobsen, 1999). With Translog, it was possible to accurately measure the length of time of pauses and hesitations and there was a record of false starts that might be an indicator of underlying processes. Where in early observational studies the researcher had to be present to note what resources the subject consulted, electronic searching made screen capture software like Camtasia essential to record sites the subjects visited online. More recently the use of eyetrackers has allowed researchers to study a variety of phenomena (O'Brien, 2009).

Both the advances of keystroke recording and eyetracking produce interesting data, without a doubt, but subjects using keystroke recording software are constrained to use the keyboard layout dictated by the software and eyetrackers require that subjects sit a certain way and depending on the model wear specific headgear. Translators used to working with computer assisted software find translating without access to their tools problematic. And if translators are given software to use that they are not familiar with, and they do not verbalize their frustration, it is impossible for a researcher to attribute a pause or a hesitation to thinking about a difficulty in a translation or a lack of familiarity with the software. So with changes in technology it becomes more difficult to say that results stem from a single variable.

Because keystroke recording software and screen capture software have been available free or at low cost to researchers, graduate students have been able to base thesis research on observational studies. The latest technological advance in the study of language processes, neuroimaging, has revolutionized the study of the neural basis of cognitive processes, but such studies are extremely expensive and require specific equipment and technical expertise.

In both the field of psychology (de Groot and Hagoort, 2017) and translation studies (Garcia, Mikulan and Ibáñez, 2016) it has been shown through such studies that many different areas of the brain are involved in storing and accessing language. In other words, translation is not a discrete, unitary faculty, and the cognitive processes which are involved in the comprehension and translation of language make use of parts of the brain which have other uses as well. One example is the difference in the parts of the brain which are activated in the comprehension of concrete and abstract words. In addition to the part of the brain where most language is under- 
stood, abstract words have been shown to activate the parts of the brain which process emotion. Some researchers have explained this difference in terms of embodiment: semantic representation, they posit, is achieved through grounding (Vigliocco et al., 2014). Concrete concepts are grounded in sensory-motor experience whereas abstract concepts are grounded in affective experience.

This brings us to a quite different metavision of cognitive processes in translation today. The field began with an assumption that the cognitive processes that made translation possible accessed dis crete structures, or systems, or relationships in the brain. Now the field is asking more philosophical questions, such as whether there is a difference between the mind and the brain (Muñoz Martín, 2016). And translation researchers have begun looking outside the individual to relationships to the outside world.

\section{Networks, ergonomics, and the changing world of translators}

The methodologies discussed so far were designed to study the individual. One goal was to describe cognitive processes in translation, another to determine the nature of expertise in translation whether in terms of strategies that better translators use or best practices across the field. Another more recent kind of research has looked at translation processes as being situated. Much like the concept of habitus which has been applied to the social context in which the translator works and views himself or herself (Simeoni, 1998), researchers have looked at the organization of the context in which a translator works and how it affects the process.

One approach to studying the context in which a professional translator works makes use of network theory (Folaron and Buzelin, 2007). This theoretical approach has been used to map relationships between translators doing the same kinds of work in different languages and/or countries (Pym, 2007, p. 746) and to show how interactions are at the centre of how translators perform their work depending on the particulars of whether they freelance or are employed by a company or organization (Risku, 2014; Risku et al., 2016). A second approach, known as cognitive ergonomics, has looked at the situatedness of translating in a given organizational environment and its effect on the individual translating processes (Ehrensberger-Dow and Massey, 2014; Ehrensberger-Dow and O'Brien, 2015). An offshoot of cognitive ergonomics uses the me- 
thods of classic observational protocols to look at consciousness of cognition as a way of improving the habits of future translators or translators looking to improve their skills (Carré, 2017).

These kinds of studies illustrate a different goal in understanding the link between translation and cognition, namely a step away from the description of competencies and internal processes to one of processes that facilitate or interfere with processes of translation. The world of translation has changed since the early days of process research where the goal was that findings would make their way into classrooms. Now there are also studies comparing the efficacy of using particular software and organizing work spaces, the nature of post-editing, etc., in other words, external influences on working conditions and the nature of tasks over time as well as translation outcomes.

When process studies were in their infancy there was a need for professional translators, and the role of education was to prepare students to enter that profession. However, as the document establishing the European Master's in Translation (European Commission, 2009) recognizes, people called translators are sometimes called on to perform tasks that aren't strictly translation. This document lists the competencies required by translators which should be part of university curricula in a Masters program, and on that list is: "Knowing how to follow market requirements and job profiles (knowing how to remain aware of developments in demand)" (ibid., n.p.).

\section{Change in the market: A snapshot of translation in the banking industry}

Knowing about developments in demand is different from identifying the competencies of excellent translators. The demand in one geographic area, one specialization, one industry will be different. To understand demand means situating the demand. Translation programs that are professionally oriented have provided, suggested, or required work placement as part of the curriculum, but that doesn't necessarily feed into skill or knowledge in the other courses. The content of translation courses includes both semantic knowledge, for example learning about terminology, and procedural knowledge, like learning to process meaning on the level of text and sentence. Both knowledge and skills can be transferable, The question for educational programs is which knowledge and which skills are valued 
in the workplace, meaning that they help graduates get jobs, advance in their careers, and help them adapt to changes in the market for multilingual communicators.

It used to be that our graduates were hired as translators, progressed up the ranks to become revisers if they were good enough, and then could hope to become department managers. All that changed with outsourcing and part-time employment. What are the possibilities of advancement for translators today? Do they need any additional skills or knowledge to be hired in a competitive market, or to be promoted? The purpose of the study that follows was to answer these kinds of questions, to take a snapshot of a representative employer of graduates in our professional programs, and to get an idea of where adjustments in the programs we offer might be useful.

\subsection{Background and methodology}

There are five major domestic banks in Canada, all of which have international operations in addition to banking operations in the country. ${ }^{1}$ As was the case throughout the corporate world, electronic communication made it possible to outsource some services, and that included translation. Where banks used to have large translation departments, most of the work had been contracted out until very recently. The manager of the translation unit of one of the largest banks came to our university to recruit graduates in translation and graduates of the program in technical and professional communication. Our discussions led to the agreement that it would be possible to conduct an in-depth study at the bank in question, onsite at bank headquarters in Toronto and by phone with translators working for the bank in the same division in Montreal. When all the information was collected from this bank, I contacted the managers of translation at two of the other major banks, Bank M and Bank S, to see whether there were significant differences and gathered information about the two remaining banks from the three other banks. All the information was gathered over a four-month period in the spring and summer of 2016.

The bank where most of the research was carried out I will refer to as Bank C. Translation is housed in a division that provides all learning, procedural, news message and social media-style content for all client-facing employees. Within the division there are sections

1. The Canadian Imperial Bank of Commerce, Royal Bank of Canada, TorontoDominion Bank (TD), Bank of Nova Scotia (Scotiabank), Bank of Montreal. 
which have responsibility for one of the following tasks: adult learning, performance consulting, technical writing, editing, and translation. The translators in this division translate web sites (at the time of the interviews there were three web sites being migrated into one), documentation for card products, branch information and information on phones. Documentation for products resides on the web and is html-based.

Information was collected through a semi-structured questionnaire over several days. Interviews began with the questionnaire but when the person being interviewed talked about a different aspect of the work at the bank, that information was deemed more important and the questions were left until the end of the interview if they weren't answered in the course of the conversation. Interviews were conducted with:

- the manager of the division

- the lead translator

- seven on-site translators in the main section of the division

- two off-site translators

- two translators in the section dealing with learning, development, and knowledge management

- two technical writers

\subsection{Summary of the results}

\section{Translator Status}

In 2010-2011 there was only one translator in the division. Today there are eleven. The division had to show that there were cost benefits to bringing in new positions. The arguments that were advanced in favour of increasing the number of full-time translators were related to productivity and to security.

\section{Productivity}

1) All translators need to be able to work with html.

2) Work has speeded up: turnaround for a lot of the translation is typically same day or the next day. The development of social media means that company news has to be translated almost instantaneously. There are 2,500 people accessing the internal news every day.

3) Some of the software that has to be used is not translation specific. 
4) Some vendors are not equipped to do revision.

5) Some vendors will not do updates when just a few words need translating. The reason is that it takes time to calculate exactly what further changes will need to be made as the result of one change. One example: if the English requires a change from the term 'credit card' to 'credit card account' it might take twenty minutes to make the change. But to make that change in French may require changes in gender agreement elsewhere, and so that change may take two to three hours.

6) Translations must work on a variety of platforms. In Bank C's division where the translators are housed there are thirty technical writers to work with the products destined for translation and the translations themselves.

\section{Security}

To address the problems of exposure to computer viruses or unauthorized access to privileged information banks:

1) Either move translation back to departments in the bank so that communication can be managed and monitored or limit the number of agencies they outsource translations to.

Bank $\mathrm{C}$ has expanded its in-house translation unit. It still contracts some work out because there are hills and valleys in requests for translation. The contracting is limited to three vendors.

Bank $M$ sends all translations out. They use two preferred vendors. It is interesting to note that the two full-time translators there have been with the bank for 20 to 30 years.

Bank S, which has 26-27 translators, prefers to do their translation in-house. They have four translation teams: legal, internal, Spanish, and web and marketing. The last team does not outsource. The bank has asked the department to use only one vendor when they outsource both for security and for standardization of terminology.

Of the two other banks, one sends all translations out and the other prefers to do all the translation in-house.

2) Banks limit software to those developed by the bank or applications vetted for all departments.

3) Banks limit electronic contact between departments except 
through dedicated paths. Controlling access makes it more difficult for outsiders to ask questions or verify terminology. The difference with employees of the bank is that a supervisor can make contacts with other departments and create a dedicated path. There is a logistical question of access to terminology and term banks that will be discussed in the section on technology.

4) Banks limit all access to transaction sites except for authorized personnel.

\section{Technology and terminology issues}

There may be compatibility issues with software across an organization. Client departments in Bank $\mathrm{C}$ submit requests for translation with screen captures rather than emails and text files, and this is the case in other banks as well. The consequence is that individual words can't be extracted from the source text and dropped into a translation. As well, if there weren't a restriction on a department adding software that is not used company-wide, Trados would not work directly with html-tagged texts. There are also administrative and accounting types of software that need input of a specific kind, like the one used to estimate the length of time a translation should take and tracks status and productivity. The unit is also in the process of implementing a request for a translation program that would result in a queue of work to which individual translators would go to pick the projects to work on, in other words a self-service distribution system.

Translators at the bank work between English and French. They would like to be able to access French grammar correctors like Antidote and style guides but as yet are prevented from doing so as the programs are not used in other places in the company. There are English language style guides in the system. As well, translators don't have access to the technical texts or applications they are explaining in French or translating into French if these texts or programs originate in departments they don't have access to. They are unable to provide the French for front-line personnel to answer queries if they do not have access to the personnel.

The combination of security restrictions impacts access to relevant information in other ways. Some banks have their own terminology banks and allow vendors access. For other banks the agencies that have service contracts with the bank manage their own 
terminology. One consistent problem with vendors is the multiple ways words that seem simple yet which might be technical in the world of the bank are translated. The example given was the word "submit", whose translations lead to ambiguous interpretations. In order to reduce problems of this kind the bank has come up with a couple of solutions. The bank may loan a translator to the agency for a certain time to ensure consistency. A second form of outreach is to invite vendors to workshops in the form of a "lunch and learn" session.

There is a related issue that causes problems for translation but also for efficiency at the banks in general. In a large organization many different people in many different departments produce documents that are saved with multiple different names about products or concepts that also have different names. Someone who needs to look up information about contracts for example might not know that some of the information is saved as "agreement". Another example from the section on adult learning was some files stored as "multi-media files" and the same type of content as "video on demand". The Project Manager at Bank B raised this issue and is in the process of producing guidelines for standardized naming conventions at the bank. She is an interesting example of someone with dual qualifications (translation and technical communication). She applied for a position as a technical writer and was given preference in the hiring process because of her expertise in French, although she wasn't expected to translate or produce anything in the language. In her current position she sends out translation work and does a first review of the quality of the translations that come back in. In her opinion, terminology was the most useful course in her translation degree, not because she works with terminology as a translator, but because she uses her understanding in her work in communication.

\section{The organization of work}

When the translation work is carried out within the bank, the system of distribution of projects is different depending on the bank. The manager may determine the distribution of projects or there may be an expediter. In the case of Bank $\mathrm{C}$, the unit is trying out a system where the individual translators will go into a bank of waiting projects and select the work they will add to their load. Departments that need something translated send their request through the software 
application and it joins the queue. At the time of my visits there were 25 projects in the queue. An issue to be ironed out with the selfservice system is that it is not easy to estimate the length of time it will take to complete a project based solely on something countable, like the number of pages or the number of words. It wasn't clear how this system would integrate with the previous flow of a project going through an intake team to a technical writer to an editor back to a technical team back to the originating department on to a quality assessment to make sure links still worked and finally to translation. Editors, some kind of quality assurance check to make sure that links are working, and the process of revision are different depending on the bank. There are separate processes to make sure that the language is acceptable, that hyperlinks work, and that the content conforms to the understanding of the department.

One of the questions I was interested in was the background of the new people hired. Were they experienced or new graduates? And how did they get integrated into the company? Did they need a special program of training, for example? The answer depended on the bank, on the availability of a manager, and on the variety of translation work. In Bank $\mathrm{C}$, some translators had previous experience elsewhere and just asked as they went along about bank practices. New graduates were most in need of understanding content, and it was suggested that they attend open meetings of departments explaining projects in the works. That way they had an opportunity to grasp concepts before finished projects showed up for translation. The processes at Bank $\mathrm{C}$ were changing rapidly. As functions such as the distribution of projects were being downloaded to each individual translator, it was expected that the publishing function was also going to be downloaded to the individual employees. Everyone, new and seasoned, would have been seeing these changes at the same time.

In Bank $\mathrm{S}$ new translators generally had experience elsewhere. They were closely mentored at the beginning. Regardless of their years of previous experience, they were given only one subject area in which to translate for six months so that they could develop expertise. After that period they were given an additional one or two areas. The manager said that the bank felt it was worth a year of coaching to bring someone up to speed.

There were opportunities for promotion, especially in the past for people who were brought in part-time or on contract, typically now a two-year term. Several people in management positions be- 
gan that way. Attitudes to promotion differed among individuals. At Bank $\mathrm{C}$ employees are expected, but not required, to apply for promotion after about five years. Not everyone is interested in leaving their current position.

In the past, a supervisor was something like a project manager and in some banks that is the title used. What is more important than the distribution of work now seems to be what two of the people in senior positions called relational management. Because of the constraints on communication between departments, the person in a managerial role needs to get to know people in other departments to establish a way to get information for the translators and the writers. It is also important to maintain relationships with vendors to ensure quality outcomes. In addition, translation is a service rather than a revenue-producing unit. There is therefore the need to justify the budget and to prove that the division is working to reduce costs and add to the benefits for the company.

In terms of promoting personal satisfaction, Bank $\mathrm{C}$ and at least one of the other banks had what was described as a generous policy that allowed people to do some of their work at home. At a supervisory level, there seems to be the possibility of taking initiatives that would make the work more personally rewarding. The person working on a standardized naming convention was able to use the knowledge from her studies to the benefit of the corporation. In Bank C, the lead translator took advantage of a company program that paid for employees to take college or university courses. He completed a diploma in technical communication, learned all the tools that were used in the various mobile platforms, and now asks why the bank doesn't move to hybrid positions rather than separating the technical and the content functions. He says he solved a problem with the translation on a Blackberry in half the time it would have taken to send the technical issues through the system to have them taken care of by the technical people.

\section{Conclusion}

It used to be that translators did the translating, revisers did the revising, writers did the writing, and a manager assigned the work. What this study shows for the banking industry is that where possible administrative functions are being downloaded and soon the publishing functions will be as well. It's possible, on the basis of what some of the interviewees have said about their own careers, 
that graduates of translation with the ability to tag for layout and for semantic knowledge in addition to the basics of technical and professional communication will have the edge in the world of multilingual communication.

But that is based on a snapshot of what is happening today. Looking to the future, most multilingual documentation will not be produced for reading, even in electronic form, but as conversation. People are already interacting with chatbots when they call to ask a company for information. This interactive oral communication will become even more common with the spread of digital personal assistants. The material used by chatbots and the artificial intelligence behind personal assistants is based on knowledge mapping. To map knowledge requires an understanding of concept topics. And producing material that can be used by chatbots and assistants means information will have to be translated into interactive questions and answers.

Through courses in terminology and a progression of courses in pragmatic translation, graduates of translator training already understand that there are variations in the way questions could be asked, and they could produce alternate forms of expression. They also know that concepts in one language may be conceived of differently in another language. Layering some additional technical skills on to a translator program as is done with such specializations as audiovisual translation or localisation might provide some interesting opportunities for translation graduates.

\section{References}

Asadi, Paula and Candace Séguinot (2005). "Shortcuts, Strategies and General Patterns in a Process Study of Nine Professionals.” Meta, 50, 2, pp. 522-547.

Alves, Fabio, ed. (2003). Triangulating Translation: Perspectives in Process Oriented Research. Amsterdam/Philadelphia, John Benjamins.

Carré, Alice (2017). L'analyse des processus cognitifs comme aide à la formation initiale et auperfectionnement des traducteurs. Ph.D. thesis. École doctorale Langues, Littératures et Sciences humaines, Université Grenoble Alpes. Unpublished. Available at <https://tel.archives-ouvertes.fr/tel01823032>.

de Groot, Annette (1997). “The Cognitive Study of Translation.”In J. Danks et al., eds. Cognitive Processes in Translation and Interpreting. Thousand Oaks, Sage Publications, pp. 25-56.

de Groot, Annette and Peter Hagoort (2017). Research Methods in Psycho- 
linguistics and the Neurobiology of Language: A Practical Guide. Hoboken/ Oxford, John Wiley \& Sons.

Ehrensberger-Dow, Maureen and Gary Massey (2014). "Cognitive Ergonomic Issues in Professional Translation.” In J. W. Schwieter and A. Ferreira, eds. The Development of Translation Competence: Theories and Methodologies from Psycholinguistics and Cognitive Science. Newcastle, Cambridge Scholars, pp. 58-86.

Ehrensberger-Dow, Maureen and Sharon O'Brien (2015). "Ergonomics of the Translation Workplace: Potential for Cognitive Friction." Translation Spaces, 4, 1, pp. 98-118.

Ericsson, K. Anders and Herbert Simon (1980). "Verbal Reports as Data." Psychological Review, 87, 3, pp. 215-251.

Ericsson, K. Anders and Herbert Simon (1984). Protocol Analysis: Verbal Reports as Data. Cambridge, MIT Press.

Ervin, Susan and Charles E. Osgood (1954). "Second Language Learning and Bilingualism." In C. Osgood and T. Sebeok, eds. Psycholinguistics: A Survey of Theory and Research Problems. Bloomington, University of Indiana Press, pp. 139-146.

European Commission (2009). Master's in Translation EMT 2009. Available at <http://ec.europa.eu/dgs/translation/programmes/emt/index_ en.htm>.

Folaron, Deborah and Hélène Buzelin (2007). "Introduction: Connecting Translation and Network Studies.” Meta, 52, 4, pp. 605-642.

Garcia, Alfredo M., Ezequiel Mikulan and Agustín Ibáñez (2016). "A Neuroscientific Toolkit for Translation Studies.” In R. Muñoz Martín, ed. Reembedding Translation Process Research. Amsterdam/Philadelphia, John Benjamins, pp. 21-46.

Göpferich, Susanne (2009). "Towards a Model of Translation Competence and its Acquisition: The Longitudinal Study TransComp." In S. Göpferich et al., eds. Behind the Mind. Methods, Models and Results in Translation Process Research. Copenhagen, Samfundslitteratur, pp. 1137.

Harris, Brian (1977). “The Importance of Natural Translation.” Working Papers on Bilingualism, 12, pp. 96-114.

Harris, Brian and Bianca Sherwood (1978). "Translating as an Innate Skill.” In D. Gerver and H.W. Sinaiko, eds. Language Interpretation and Communication. New York, Plenum, pp. 155-170.

Jääskeläinen, Riitta (1990). Features of Successful Translation Processes: A Think-Aloud Protocol Study. Licentiate Thesis. Savonlinna School of Translation Studies, University of Joensuu. Unpublished.

Jäskeläinen, Riitta (1999). Tapping the Process: An Explorative Study of the Cognitive and Affective Factors Involved in Translating. Joensuu, University of Joensuu. 
Jensen, Astrid and Arnt Lykke Jakobsen (2000) “Translating under Time Pressure." In A. Chesterman et al., eds. Translation in Context: Selected Contributions from the EST Congress 1998. Amsterdam/Philadelphia, John Benjamins, pp. 105-116.

Jakobsen, Arnt Lykke (1999). "Logging Target Text Production with Translog." In G. Hansen, ed. Probing the Process in Translation: Methods and Results, Copenhagen Studies in Language, 24. Copenhagen, Samfundslitteratur, pp. 9-20.

Jakobsen, Arnt Lykke (2003) "Effects of Think Aloud on Translation Speed, Revision, and Segmentation.” In F. Alves, ed. Triangulating Translation. Perspectives in Process Oriented Research. Amsterdam/Philadelphia, John Benjamins, pp. 69-95.

Levý, Jiř́ (1967). “Translation as a Decision Process.” In To Honour Roman Jakobson, vol. II. The Hague, Mouton, pp. 1171-1182.

Muñoz Martín, Ricardo (2016). "Reembedding Translation Process Research: An Introduction.” In R. Muñoz Martín, ed. Reembedding Translation Process Research. Amsterdam/Philadelphia, John Benjamins, pp. 1-19.

Newell, Allen and Herbert Simon (1972). Human Problem Solving. Englewood Cliffs, Prentice Hall.

Newmark, Peter (1988). A Textbook of Translation. New York, Prentice Hall. O'Brien, Sharon (2009). "Eye Tracking in Translation Process Research: Methodological Challenges and Solutions." In I. Mees et al. eds. Methodology, Technology and Innovation in Translation Process Research: a Tribute to Arnt Lykke Jakobsen. Copenhagen Studies in Language, 38. Samfundslitteratur, Copenhagen, pp. 251-266.

Pacte (2008). "First Results of a Translation Competence Experiment: Knowedge of Translation and Efficacy of the Translation Process." In J. Kearns, ed. Translator and Interpreter Training. Issues, Methods and Debates. London, Continuum, pp. 104-126.

Pym, Anthony (2007). "Cross-cultural Networking: Translators in the French-German Network of Petites Revues at the End of the Nineteenth Century." Meta, 52, 4. pp. 744-762.

Risku, Hanna (2014). "Translation Process Research as Interaction Research: From Mental to Socio-cognitive Processes." MONTI Special Issue,1, pp. 331-353.

Risku, Hanna, Regina Rogl and Christina Pein-Weber (2016). "Mutual Dependencies: Centrality in Translation Networks." The Journal of Specialised Translation, 25, 1, pp. 1-22.

Séguinot, Candace (1988). "Translating the Ideology of Science: The Example of the Work of Alfred Tomatis." TTR, 1,1, pp. 103-112.

Simeoni, Daniel. (1998). "The Pivotal Status of the Translator's Habitus." Target, 10, 1, pp. 1-39. 
Vigliocco, Gabriella et al. (2014). "The Neural Representation of Abstract Words: The Role of Emotion.” Cerebral Cortex, 24, 7, pp. 1767-1777.

Vinay,Jean-Paul and Jean Darbelnet (1958). Stylistique comparée du français et de l'anglais. Méthode de traduction. Paris, Didier; Montréal, Beauchemin.

Vinay, Jean-Paul and Jean Darbelnet (1995). Comparative Stylistics of French and English, a Methodology for Translation. Trad. and ed. Juan C. Sager and M.-J. Hamel. Amsterdam/Philadelphia, John Benjamins.

Werner, Oswald and G. Mark Schoepfle (1987). Systematic Fieldword. Vol. 1: Foundations of Ethnography and Interviewing. Vol. 2: Ethnographic Analysis and Data Management. Newbury Park, Sage Publications.

\author{
Candace Séguinot \\ Professor Emerita \\ School of Translation \\ York University \\ Toronto (Ontario), Canada \\ seguinot@glendon.yorku.ca
}




\section{APPENDIX}

\section{Survey questions}

1) What is the process for the distribution of work?

2) Is there a style guide or a protocol or a mentoring process for new staff?

3) Have the workstations always been configured the way they are or have they been changed? If they have been changed, do you find the change better or worse for you?

4) What software is available on your workstation?

5) Are there ways you would prefer to work but can't? Why?

6) What did you need to learn when you came here to work that you wish you'd learned before?

7) Who decides what work needs to be translated and what work is written in another language in a freer form of adaptation?

8) How is work revised?

9) Where are the gaps in the process of assigning and verifying the work?

10) What benefits are available with seniority?

11) Can you expect to be promoted? If you are promoted, would the new position be in the same department or in a different department? What additional skills would you need to be promoted? 